\title{
Correction to: Assessing the Contribution of Sli to Self-Compatibility in North American Diploid Potato Germplasm Using KASP ${ }^{\mathrm{TM}}$ Markers
}

\author{
N. R. Kaiser ${ }^{1} \cdot$ S. Jansky ${ }^{2,3}$ - J. J. Coombs ${ }^{1} \cdot$ P. Collins ${ }^{1} \cdot$ M. Alsahlany ${ }^{1,4} \cdot$ D. S. Douches ${ }^{1}$
}

Published online: 16 March 2021

(C) The Potato Association of America 2021

\section{Correction to: American Journal of Potato Research} https://doi.org/10.1007/s12230-021-09821-8

Due to a Production error the Spanish-language Abstract was omitted from the original publication of this article. The article has been revised and is now complete.

The online version of the original article can be found at https://oi.org/ $10.1007 / \mathrm{s} 12230-021-09821-8$

N. R. Kaiser

kirkwyla@msu.edu

1 Department of Plant, Soil and Microbial Sciences, Michigan State University, 1130 C Molecular Plant Sciences, 1066 Bogue Street,

East Lansing, MI 48824, USA

2 Department of Horticulture, University of Wisconsin-Madison, Madison, WI 53706, USA

3 United States Department of Agriculture-Agricultural Research Service, Vegetable Crops Research Unit, Madison, WI 53706, USA

4 Cavendish Farms Corporation, New Annan, Prince Edward Island C1N 4J9, Canada 